\title{
Bioactivity of Scytonema hofmanni (Cyanobacteria) in Lilium alexandrae in vitro propagation
}

\author{
María Cristina Zaccaro* \\ Laboratorio de Fisiología Vegetal y Biología de Cyanobacteria \\ Departamento de Biodiversidad y Biología Experimental \\ Facultad de Ciencias Exactas y Naturales FCEN \\ Universidad de Buenos Aires \\ Intendente Güiraldes 2620 Pab. II $4^{\circ} \mathrm{P}$ Lab 2 \\ Ciudad Universitaria C1428EHA \\ Buenos Aires, Argentina \\ Tel: 0054 1145763300/09 ext. 201 \\ Fax: 00541145763384 \\ E-mail: cyanob@bg.fcen.uba.ar
}

\author{
Adriana Kato \\ Instituto de Floricultura \\ INTA-Castelar \\ Las Cabañas y De los Reseros s/n (1712) \\ Buenos Aires, Argentina \\ Tel/Fax: 5411 4481/3736 \\ E-mail: akato@castelar.inta.gov.ar
}

\section{Gloria Zulpa}

Laboratorio de Fisiología Vegetal y Biología de Cyanobacteria Departamento de Biodiversidad y Biología Experimental

Facultad de Ciencias Exactas y Naturales FCEN Universidad de Buenos Aires

Intendente Güiraldes 2620 Pab. II $4^{\circ} \mathrm{P}$ Lab 2

Ciudad Universitaria C1428EHABuenos Aires, Argentina

Tel: 0054 1145763300/09 ext. 201

Fax: 00541145763384

E-mail: cyanob@bg.fcen.uba.ar

\section{Mónica Magdalena Storni}

Laboratorio de Fisiología Vegetal y Biología de Cyanobacteria Departamento de Biodiversidad y Biología Experimental

Facultad de Ciencias Exactas y Naturales FCEN Universidad de Buenos Aires

Intendente Güiraldes $2620 \mathrm{Pab}$. II $4^{\circ} \mathrm{P}$ Lab 2

Ciudad Universitaria C1428EHA

$$
\text { Buenos Aires, Argentina }
$$

Tel: 0054 1145763300/09 ext. 201

Fax: 00541145763384

E-mail: cyanob@bg.fcen.uba.ar

\section{Noemí Steyerthal}

Laboratorio deAnálisis Biológicos

Departamento de Química Biológica

Facultad de Ciencias Exactas y Naturales

Universidad de Buenos Aires

Intendente Güiraldes $2620 \mathrm{Pab}$. II $4^{\circ} \mathrm{P}$ Lab 2

Ciudad Universitaria C1428EHA

Buenos Aires, Argentina

Tel: 0054 1145763300/09 ext. 201

Fax: 00541145763384

\section{Karina Lobasso}

Laboratorio de Fisiología Vegetal y Biología de Cyanobacteria Departamento de Biodiversidad y Biología Experimental

Facultad de Ciencias Exactas y Naturales Universidad de Buenos Aires

* Corresponding author 


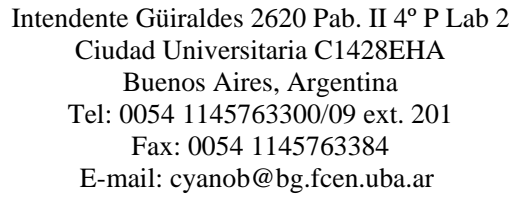

\author{
Ana María Stella \\ Laboratorio de Ecoporfirinas \\ Departamento de Química Biológica \\ Facultad de Ciencias Exactas y Naturales \\ Universidad de Buenos Aires - CONICET \\ Intendente Güiraldes $2620 \mathrm{Pab}$. II $4^{\circ} \mathrm{P}$ Lab 2 \\ Ciudad Universitaria C1428EHA \\ Buenos Aires, Argentina \\ Tel: 0054 1145763300/09 ext. 201 \\ Fax: 00541145763384 \\ E-mail: stella@qb.fcen.uba.ar
}

Financial support: UBACyT X64, Universidad de Buenos Aires, Argentina.

Keywords: ascorbate peroxidase, bioactive substances, bulb regeneration, catalase, Cyanobacteria, glutathione reductase, Lilium alexandrae, Scytonema hofmanni.

Abbreviations: BWE: biomass water extract.
EP: extracellular products.
NAA: naphthalene acetic acid.
MS: Murashige-Skoog.

Cyanobacteria produces bioactive compounds including plant growth regulators. Naphthalene acetic acid (NAA), a toxic substance, is a synthetic plant regulator used in micropropagation. The aim of this work was to evaluate morphogenetic and antioxidant effects produced by intra and extracellular substances from Scytonema hofmanni (Cyanobacteria) during the multiplication in vitro of Lilium alexandrae and to compare them to those produced by NAA. Intra and extracellular cyanobacterial products increased a) bulblets production reaching $83 \%$ and $78 \%$ of NAA effect, respectively; b) the bulblet diameter compared to NAA; and c) the bulblet survival due to the promotion of antioxidant activity measured as catalase, ascorbate peroxidase, and glutathione reductase activity. The cyanobacterial substances stimulated regeneration and delayed bulblet senescence. They could replace NAA, dangerous for the operator, not only during the regeneration phase but also during the storage of the viable bulblets cultivated in vitro.

Growth regulators which accelerate the production of a number of agronomical interesting plants are used in in vitro culture of plants. Growth regulators are mainly obtained by chemical synthesis. Cyanobacteria produce a variety of bioactive compounds including growth phytoregulators (Metting and Pyne, 1986), that could be used in the in vitro production of vegetables, fruits, fungi and ornamental flowers. Already in 1979, Zulpa de Caire et al. (1979) established that Nostoc muscorum Ag. liberated into the culture medium auxin-like substances. It has recently demonstrated that a number of Cyanobacteria produce, accumulate, and liberate 3-indol acetic acid (Sergeeva et al. 2002). Arthronema africanum produces the cytokinin isopentenyl adenine (Stirk et al. 1999). Stirk et al. (2002) found auxin and cytokinin activity by three cyanobacterial strains. It is important to mention that some cyanobacterial products promote regeneration in Daucus carota (Wake et al. 1992), Santalum album (Bapat et al. 1996), Oryza sativa (Zaccaro et al. 2002; Storni de Cano et al. 2003), Lilium alexandrae hort. Wallace, from Japan, is an ornamental plant, with white flowers bending down to form an angle of $90^{\circ}$, with respect to the vertical axis of the plant making this species a very interesting one for the improvement of other Lilium species (Nakayama, 1989). Naphthalene acetic acid (NAA) is a synthetic phyto-regulator very much used in micropropagation. Toxicological information indicates that NAA causes contact irritation of skin, eyes, mucous membranes, as well as the upper respiratory tract. It also attacks the central nervous system and can be absorbed by the operators skin (Sigma - Aldrich-Argentina S.A.). The aim of this work was to evaluate the morphogenetic and antioxidant effects produced by intra and extracellular substances from Scytonema hofmanni (Cyanobacteria), on the in vitro propagation of L. alexandrae and to compare them with those produced by synthetic phyto-regulators.

\section{MATERIALS AND METHODS}

\section{Explant obtention}

Microscales (6-8 x 6-10 mm) from bulblets of $L$. alexandrae (1.8-2.5 g fresh weight and 5-6.2 cm diameter), were obtained in vitro after 120 days growing on MS medium (Murashige and Skoog, 1962), with a photoperiod 
Table 1. Activity of antioxidant enzymes in bulblets at day 260. Different letters indicate significant differences $(p<0.05)$.

\begin{tabular}{|c|c|c|c|}
\hline Treatment & $\begin{array}{c}\text { Catalase } \\
\text { (umol/min g fresh weight) }^{\text {(umol/min } \text { g fresh weight) }}\end{array}$ & $\begin{array}{c}\text { Ascorbate peroxidase } \\
\text { (umoluthione reductase } \\
\text { (umol/min g fresh weight) }\end{array}$ \\
\hline MS & $7.212 \pm 0.003^{\mathrm{d}}$ & $10.604 \pm 0.010 \mathrm{~d}$ & $2.212 \pm 0.700 \mathrm{C}$ \\
\hline MS + NAA & $15.511 \pm 0.003^{\mathrm{c}}$ & $44.051 \pm 0.005 \mathrm{a}$ & $3.384 \pm 0.050 \mathrm{C}$ \\
\hline MS + EP & $59.852 \pm 0.005^{\mathrm{a}}$ & $16.784 \pm 0.005 \mathrm{c}$ & $14.034 \pm 0.060 \mathrm{~A}$ \\
\hline MS + BWE & $24.893 \pm 0.004^{\mathrm{b}}$ & $32.623 \pm 0.005 \mathrm{~b}$ & $5.854 \pm 0.050 \mathrm{~B}$ \\
\hline
\end{tabular}

of 12 hrs light and a light intensity of $45 \mu \mathrm{mol}$ photon $\mathrm{x} \mathrm{m}^{-2}$ $\operatorname{seg}^{-1}$ and $25 \pm 1^{\circ} \mathrm{C}$. The abaxial side of the explant was placed on the culture medium.

\section{Obtaining of cyanobacterial products}

Biomass water extracts (BWE) and extracellular products (EP). S. hofmanni Ag. ex Born. et Flahault axenic strain $\mathrm{N}^{\circ} 58$, from the culture collection belonging to Laboratorio de Cyanobacteria, Facultad de Ciencias Exactas y Naturales, Universidad de Buenos Aires, Argentina, was cultivated in modified Watanabe medium (Storni de Cano et al. 2003), photoperiod 12 hrs light, 45 $\mu$ mol photon $\mathrm{x} \mathrm{m}^{-2} \mathrm{seg}^{-1}, 27 \pm 1^{\circ} \mathrm{C}$. After 30 days growing in that medium, the biomass was separated from the culture medium by centrifugation at $10.000 \mathrm{xg}$ at $5^{\circ} \mathrm{C}$. The fresh biomass was homogenized with alumina ( $1 \mathrm{~g}$ biomass / $3 \mathrm{~g}$ alumina), and extracted with sterile distilled water (1 g fresh biomass / $5 \mathrm{ml}$ water). After centrifugation the supernatant BWE was obtained. The culture medium contained the extracellular products (EP). BWE and EP were sterilised by ultrafiltration $(0.22 \mu \mathrm{m})$.

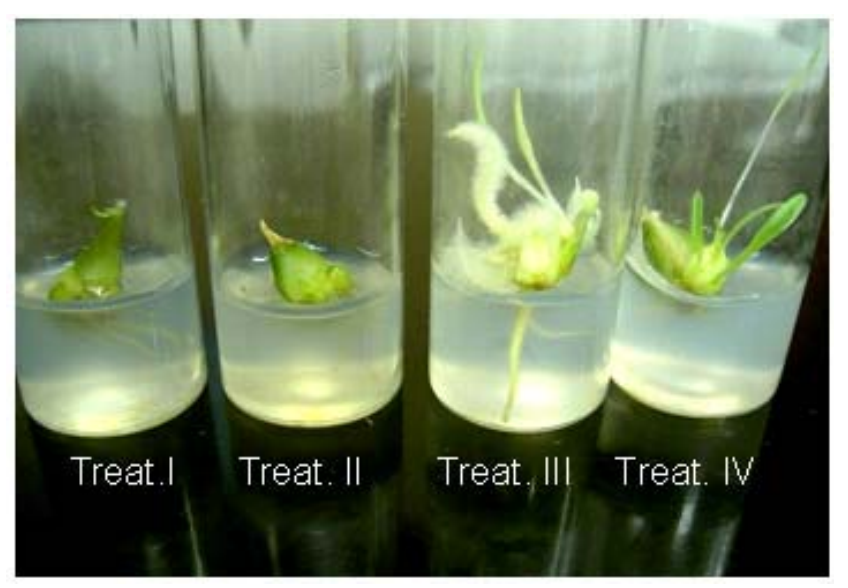

Figure 1. Bulblets, leaves and roots differentiation in micro scales from $L$. alexandrae. Treatments: I (MS), II (MS + EP), III $(\mathrm{MS}+\mathrm{NAA})$ and IV (MS + BWE), at day 50.

\section{Obtaining of bulblets}

Treatments: I, $8 \mathrm{ml}$ MS $+2 \mathrm{ml}$ distilled water. II, $8 \mathrm{ml} \mathrm{MS}$ $+2 \mathrm{ml}$ EP. III, $8 \mathrm{ml} \mathrm{MS}+2 \mathrm{ml}$ distilled water $+0.1 \mathrm{mg} / \mathrm{L}$ NAA. IV, $8 \mathrm{ml}$ MS $+2 \mathrm{ml}$ BWE. The media contained 3\% sucrose, $0.7 \%$ agar and $\mathrm{pH}$ was adjusted to 6.8 , before being sterilized in tubes $(14 \times 2.5 \mathrm{~cm})$. The explants were placed in a dark culture chamber, for three weeks in order to obtain differentiation and bulblets growth. After that period they were transferred to $16: 8$ photoperiod, $45 \mu \mathrm{mol}$ photon $\mathrm{x} \mathrm{m}^{-2} \mathrm{seg}^{-1}$ and $25 \pm 1^{\circ} \mathrm{C}$. Each 5 weeks, they were transferred to fresh medium. At days 20, 30, 40, 50 and 70 the number of bulblets per explant, bulblet longest diameter, bulblet roots and leaves length and number per explant were measured. At day 260 in this case without transference to fresh medium, the survival capacity of the bulblets in each treatment was established.

\section{Biochemical parameters}

Enzymatic activity of catalase, ascorbate peroxidase and glutathione reductase were determined according to Beers and Sizer (1951), Nakano and Asada (1981) and Schaedler and Bassham (1977), respectively, in order to establish the bulblets oxidative stress level produced by the regeneration treatments.

\section{Statistic analysis}

Analysis of variance was performed for all data, using a completely randomized experimental design. A one-way ANOVA was performed (PC program GraphPad Prism). A Tukey HDS test $(p<0.05)$ was used to compare different treatments for each day, $\mathrm{n}=14$.

\section{RESULTS AND DISCUSSION}

At day 50 (Figure 1) S. hofmanni BWE increased the number of bulblets per explant by $27 \%$ comparing with MS, representing this increment $78 \%$ of the bulblets produced by NAA. At day 70 the increment was 21 y $32 \%$ for EP and BWE, respectively, compared to MS. With respect to NAA, EP produced $78 \%$ and BWE $83 \%$ of the number obtained with the synthetic auxin (Figure 2a). No matter higher the number of bulblets produced by NAA, cyanobacterial intracellular products increased the number of bulblets thicker than $5 \mathrm{~mm}$ as at day 70 BWE surpassed NAA, MS and EP effect by nearly 30\% (Figure $2 b$ ). This effect on thickness is important to survival of the bulblets. The number of roots per explant (Figure 2c) in MS and EP was lesser than NAA by $70 \%$ and in BWE by $50 \%$, at day 70. This could mean that BWE favoured the higher thickness of the bulblets, compared to NAA, at the expense 
of the number of roots, probably due to a differential distribution of organic nutrients. The number of leaves per explant (Figure 2d) was the same in EP and NAA at day 70, showing at the beginning an acceleration of differentiation with EP. Extracellular products from other Cyanobacteria were shown to replace synthetic phyto-regulators in the organogenesis of rice calli (Storni de Cano et al. 2003), to increase the phyto-regulators content of Lupinus termis (Haroun and Hussein, 2003). Cyanobacterial crude extracts showed auxinic activity in potato tissue culture (Shanab et al. 2003). At day 260 the number of bulblets decreased in all the treatments. In MS 50\% bulblets were necrotic and in NAA $100 \%$, but with EP and BWE $90 \%$ were viable. Table 1 shows that EP and BWE produced an increment of 3.85 and 1.60 fold in catalase activity with respect to NAA which in turn doubled this activity with respect to MS. Bulblets ascorbate peroxidase activity increased 4 times with NAA, 3 times with BWE and 1.67 times with EP. Glutathione reductase activity increased 6.34 times with
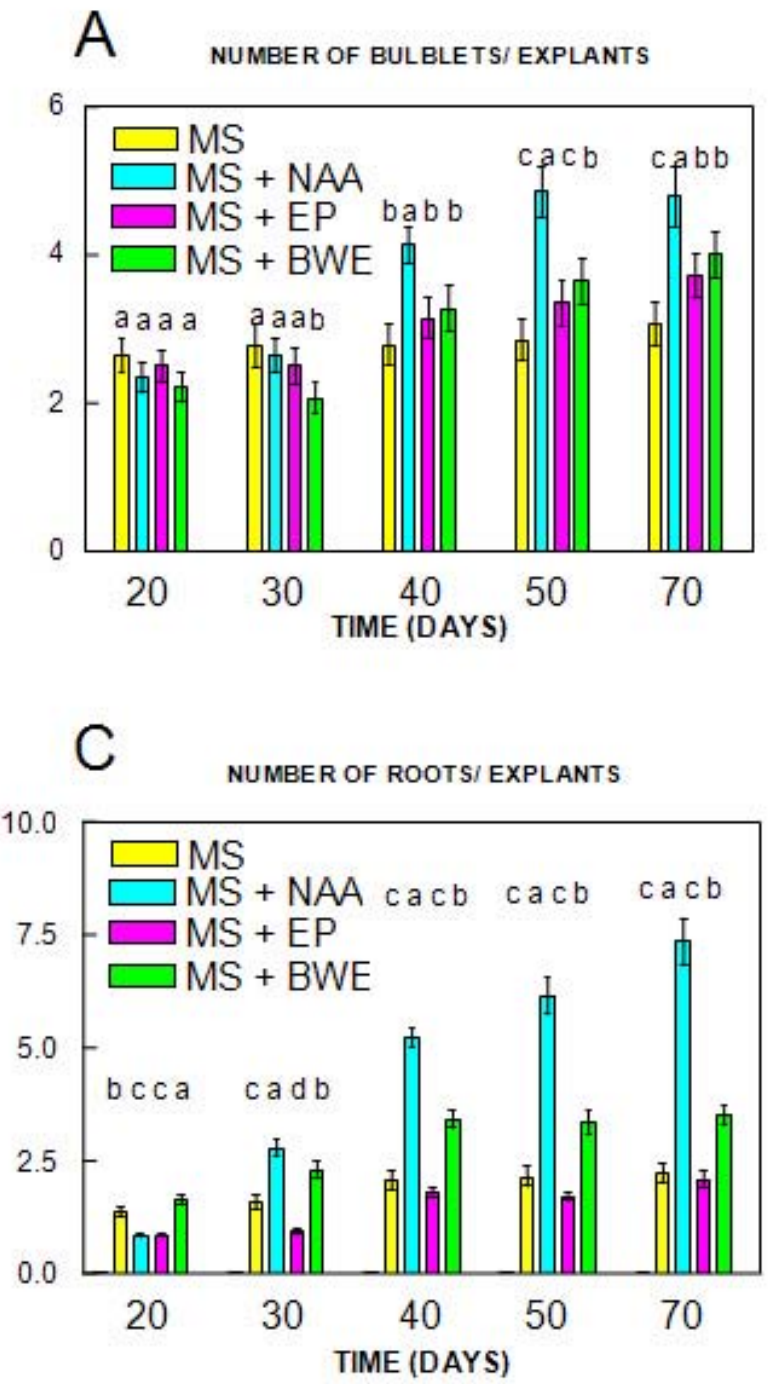

EP, 2.64 times with BWE and 1.52 times with NAA comparing with the control with MS. The activity of enzymes related with reactive oxygen species was remarkably incremented by cyanobacterial products, surpassing NAA for catalase and glutathione reductase activity which could explain the higher survival of bulblet that were not transferred to fresh medium for 260 days remaining viable by $90 \%$. It is known that the activity of antioxidant enzymes increases in tissues under different stress conditions, such as sugar beet calli (Hagége, 1996).

\section{CONCLUDING REMARKS}

Intra and extracellular products from $S$. hofmanni increment L. alexandrae bulblets production from microscales, comparing with control without synthetic phyto-regulators as well as bulblets survival in culture because they promote a higher antioxidant activity. This effect could be due to the production and liberation of plant growth regulators such as
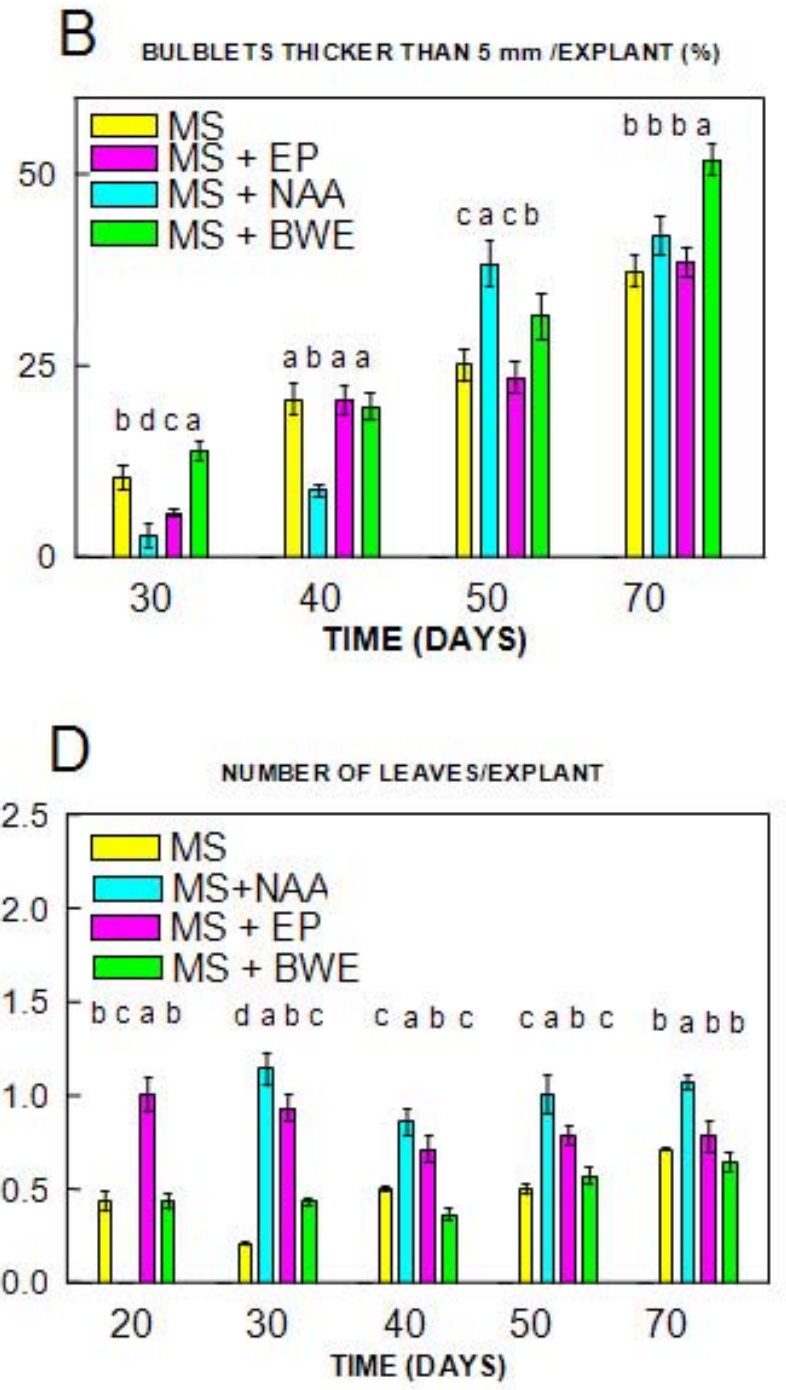

Figure 2. Morphogenetic development of explants from bulblets of $L$. alexandrae. Different letters indicate significant differences $(p<0.05)$. 
auxin-like and cytokinin-like substances by the cyanobacterium, which produced similar results than those obtained with the synthetic auxin NAA and also because the bulblets senescence was delayed, an effect well-known for cytokinin. Besides, the cyanobacterial phyto-regulators could replace substances that result dangerous to the operator not only during the regeneration phase but also during the storage of the viable bulblets cultivated in vitro.

\section{REFERENCES}

BAPAT, V.A.; IYER, R.K. and RAO, P.S. Effect of cyanobacterial extract on somatic embryogenesis in tissue culture of sandalwood (Santalum album). Journal of Medicinal and Aromatic Plant Sciences, 1996, vol. 18, no. 1, p. 10-14.

BEERS, R.F. and SIZER, I.W. A spectrophotometric method for measuring the breakdown of hydrogen peroxide by catalase. Journal of Biological Chemistry, 1951, vol. 195, no. 1, p. 133-140.

HAGÉGE, D. Habituation in sugar beet plant cells: permanent stress or antioxidant adaptive strategy? In vitro Cellular and Developmental Biology - Plant, 1996, vol. 32, no. 1, p.1-5.

HAROUN, S.A. and HUSSEIN, M.H. The promotive effect of algal biofertilizers on growth, protein pattern and some activities of Lupinustermis plants grown in siliceous soil. Asian Journal of Plant Sciences, 2003, vol. 2, no. 13, p. 944-951.

METTING, B. and PYNE, J.W. Biologically active compounds from microalgae. Enzyme and Microbial Technology, 1986, vol. 8, p. 386-394.

MURASHIGE, T. and SKOOG, F. A revised medium for rapid growth and bioassays with tobacco tissue cultures. Physiologia Plantarum, 1962, vol. 15, p. 473-497.

NAKANO, Y. and ASADA, T. Hydrogen peroxide is sacavenged by ascorbate specific - peroxidase in spinach chloroplast. Plant Cell Physiology, 1981, vol. 22, no. 5, p. 867-880.

NAKAYAMA, S. Genus Lilium L. Lilium alexandrae. In: TSUKAMOTO, Y. ed. The grand dictionary of horticulture. Shogakukan, Tokyo, Japan, 1989, vol. 5, p. 198-209. ISBN 4-09-305105-4.

SERGEEVA, E.; LIAIMER, A. and BERGMAN, B. Evidence for production of phytohormone indol-3-acetic acid by cyanobacteria. Planta, 2002, vol. 215, no. 2, p. 229238.

SHAEDLER, M. and BASSHAM, J. Chloroplast gluthationereductase. Plant Physiology, 1977, vol. 59, p. 1011-1012.

SHANAB, S.; SAKER, M.M. and ABDEL-RAHMAN, M. Crude extract of some fresh water cyanobacteria have auxin like activity on potato tissue culture. Arabian Journal of Biotechnology, 2003, vol. 6, no. 2, p. 297-312.

STIRK, W.A.; ÖRDÖG, V. and VAN STADEN, J. Identification of the cytokinin isopentenyladenine in a strain of Arthronemaafricanum (Cyanobacteria). Journal of Phycology, 1999, vol. 35, no. 1, p. 89-92.

STIRK, W.A.; ÖRDÖG, Vince; VAN STADEN, J. and JÄGER, K. Cytokinin- and auxin-like activity in Cyanophyta and microalgae. Journal of Applied Phycology, 2002, vol. 14, no. 3, p. 215-221.

STORNI DE CANO, Mónica; ZACCARO, María Cristina; GARCÍA, Ileana; STELLA, Ana María and ZULPA DE CAIRE, Gloria. Enhancing rice callus regeneration by extracellular products of Tolypothrixtenuis (Cyanobacteria). World Journal of Microbiology and Biotechnology, 2003, vol. 19, no. 1, p. 29-34.

WAKE, H.; AKASAKA, A.; UMETSU, H.; OZEKI, Y.; SHIMOMURA, K. and MATSUNAGA, T. Promotion of plantlet formation from somatic embryos of carrot treated with a high molecular weight extract from a marine cyanobacterium. Plant Cell Reports, 1992, vol. 11, no. 2, p. 62-65.

ZACCARO, María Cristina; STELLA, Ana María; GARCÍA, Ileana; EBERLE, Ariel; DÍAZ, Marina; STORNI DE CANO, Mónica and ZULPA DE CAIRE, Gloria. Organogenesis induction in rice callus by cyanobacterial extracellular products. Phytomorphology, 2002, vol. 52, no. 4, p. 263-271.

ZULPA DE CAIRE, Gloria; ZACCARO DE MULÉ, María Cristina and STORNI DE CANO, Mónica. Productos extracelulares de Nostoc muscorum Ag. (сера 79a) obtenidos en medios con y sin nitrógenocombinado. I: Sus efectos sobre plántulas de arroz. Phyton, 1979, vol. 37, no. 1, p. 1-13. 